\title{
Contributors
}

\section{Kristin Bech}

- University of Oslo

Kristin Bech is associate professor of English language. She specializes in the development of syntactic structures in the history of English, with a focus on Old and Middle English, but she is also interested in cross-linguistic comparisons. She has previously run a project on the relation between syntax and information structure in old Germanic and Romance languages, and has recently started a new project on the structure of noun phrases in old Germanic languages.

\section{Kaja Borthen}

- Norwegian University of Science and Technology

Kaja Borthen is professor in linguistics at the section for Scandinavian Languages of Department of Language and Literature. She has worked on syntactic, semantic and pragmatic aspects of nominal phrases, using Head-driven Phrase Structure Grammar as her main syntactic framework, and on topics related to automatic anaphora resolution. Her most recent research has focused on non-truth conditional semantics and pragmatics, including topics such as implicature, the semantics and pragmatics of referring expressions, and the semantics and pragmatics of pragmatic particles.

\section{Robin Cooper}

\section{- University of Gothenburg}

Robin Cooper is senior professor at the University of Gothenburg, where he was previously professor of computational linguistics. He is currently conducting research within the Centre for Linguistic Theory and Studies in Probability (CLASP) at the Department of Philosophy, Linguistics and Theory of Science. His main research interests are semantics (both theoretical and computational), dialogue semantics and computational dialogue systems. Currently he is working on a type theoretical approach to language and cognition. 


\section{Mary Dalrymple}

- University of Oxford

Mary Dalrymple is professor of syntax at the Faculty of Linguistics. Her research centers on syntax, the syntax-semantics interface, and semantics, particularly within the framework of Lexical Functional Grammar. She is interested in the syntactic properties of human languages and how they can guide the process of assembling meanings of words and phrases into meanings of larger phrases and sentences. She is also interested in language description and documentation, and in Austronesian and Papuan languages.

\section{Cheikh M. Bamba Dione}

- University of Bergen

Cheikh M. Bamba Dione is lecturer in linguistics and computational linguistics at the Department of Linguistic, Literary and Aesthetic Studies. His interests include theoretical and computational linguistics as well as psycholinguistics. He has done extensive work on Wolof morphology and grammar. His most recent research focused on the implementation of computational models to develop digital language resources. He is also conducting studies on the use of statistical and machine learning approaches to develop language technology applications. In the area of psycholinguistics, his research interests are language comprehension and production, interaction of language and thought, and mechanisms that influence human language representation and processing.

\section{Elisabet Engdahl}

\section{- University of Gothenburg}

Elisabet Engdahl is professor emerita at the Department of Swedish. She is interested in Scandinavian linguistics, in particular variation in word order and information structure. She has been involved in the Scandinavian Dialect Syntax project and in the development of the Nordic Dialect Corpus and the Nordic Syntax Database, two internet resources maintained at the Text Laboratory at the University of Oslo. With this article she resumes an old collaboration with Annie Zaenen and Joan Maling, dating back to a joint paper published in 1981.

\section{Dag Trygve Truslew Haug}

\section{- University of Oslo}

Dag Haug is a professor of Greek and Latin at the Department of Philosophy, Classics, History of Art and Ideas. His work focuses on formal syntax (using Lexical Functional Grammar) and semantics, as well as historical linguistics. He works both on the classical languages and on issues of more general theoretical interest, in particular anaphora, control and binding. He leads the development of the PROIEL treebank of ancient Indo- 
European languages, which aims to offer scholars who work on these languages with a solid empirical basis for their research.

\section{Petter Haugereid}

- Western Norway University of Applied Sciences

Petter Haugereid is associate professor in the Norwegian Department, teaching Norwegian since 2014. He has had postdoc positions at NTU, Singapore from 2010 to 2012, Haifa University from 2012 to 2013 and the University of Bergen from 2013 to 2014. He has worked on machine translation, computational grammars and syntactic annotation of Norwegian corpora. His thesis at NTNU, Trondheim, from 2009 was on phrasal subconstructions and presented a constructionalist grammar design, exemplified with Norwegian and English. His publications are mainly in the field of formal grammar, machine translation, and corpora.

\section{Christer Johansson}

- University of Bergen

Christer Johansson is professor of computational linguistics. Previously he was a post-doc researcher at the Institute of Advanced Industrial Science and Technology in Tsukuba, Japan, and a member of Laurie Ann Stowe's research group at Rijksuniversiteit Groningen. His doctoral dissertation from Lund University in 1997 modeled learnability of language. His research interests include cognitive science, experimental psycholinguistics and statistical models of language. His teaching aims to combine research and teaching, which has resulted in several MA-theses and conference contributions on themes related to crosslinguistic priming, code switching, reference as well as theory testing.

\section{Ronald M. Kaplan}

\section{- Amazon.com and Stanford University}

Ronald M. Kaplan is currently Chief Scientist for Search Technologies at Amazon.com and adjunct professor of linguistics at Stanford University. For many years he directed the Natural Language Theory and Technology research group at the Xerox Palo Alto Research Center. He created the modular architecture of Lexical Functional Grammar and introduced many of its formal devices for linguistic description. His research centers on the mathematical and computational properties of the LFG formalism and its ability to support well-motivated accounts for a wide range of linguistic phenomena.

\section{Torodd Kinn}

- University of Bergen

Torodd Kinn is professor of Scandinavian linguistics. His research has three foci. The first is in Scandinavian morphology and syntax, with studies centered on pseudopar- 
titives (binominal constructions), grammaticalization, and pseudocoordination (complex predication). The second focus is in text linguistics, with studies of scientific writing (especially prononun use) in Norwegian, English, and French research articles in the fields of economics, medicine, and linguistics. The third focus is in anthroponymy, with the development of innovative methods in historical Norwegian given-name geography.

\section{Helge Lødrup}

- University of Oslo

Helge Lødrup is professor of general linguistics in the Department of Linguistics and Scandinavian Studies. His field of research is the grammar of Norwegian and related languages within generative grammar, especially Lexical Functional Grammar. He has published on various topics, mainly within Norwegian syntax, such as passive and impersonal sentences, reflexives, body part nouns and kinship nouns, external possessors and other possessive expressions, surface anaphora, clausal complementation, complex predicates, and pseudocoordination.

\section{Joan Maling}

\section{- Brandeis University and National Science Foundation}

Joan Maling is professor emerita of linguistics in the Linguistics Program, where she taught from 1972 until 2003. Since June 2003 she has been director of the Linguistics Program at the National Science Foundation, where she was instrumental in starting the Documenting Endangered Languages Program. She has published on many aspects of the syntax of Modern Icelandic, especially case, word order, passive, prepositionstranding and long distance reflexives, and on case alternations in Finnish, Korean and German as well as Icelandic. In 2009, she was awarded an honorary doctorate by the University of Iceland for her contributions to Icelandic linguistics.

\section{Paul Meurer}

\section{- Uni Research Computing and University of Bergen}

Paul Meurer is a researcher at Uni Research Computing and at the University of Bergen, Department of Linguistic, Literary and Aesthetic Studies. His research interests lie in the fields of theoretical and computational linguistics. Within theoretical linguistics, he has focused on morphology and syntax, and language typology. In computational linguistics, he has contributed to the research and development of language resources and tools in diverse fields, such as morphological and syntactic parsing for Norwegian, Georgian and Abkhaz, treebanking, vizualization, corpus management and search, terminology, and metadata curation. He received the Steven Krauwer Award for CLARIN Achievements in 2017. 


\section{Adam Przepiórkowski}

- Polish Academy of Sciences and University of Warsaw

Adam Przepiórkowski holds the professor position both at the Institute of Computer Science of the Polish Academy of Sciences and at the Institute of Philosophy of the University of Warsaw, where he teaches linguistics at the Cognitive Science programme. He headed the National Corpus of Polish project, he worked within Head-driven Phrase Structure Grammar on case, negation, etc., and he currently works within Lexical Functional Grammar on the argument-adjunct (non)distinction, on coordination, distributivity, case assignment and other issues at the syntax-semantics interface.

\section{Victoria Rosén}

\section{- University of Bergen}

Victoria Rosén is associate professor of linguistics at the Department of Linguistic, Literary and Aesthetic Studies. Her main research interest is syntax in the Lexical Functional Grammar framework, and her dissertation concerned an LFG analysis of topics and empty pronouns in Vietnamese. In later work she has focused on the grammar of Norwegian in language technology projects dealing with automatic proofreading, machine translation, computational grammar and treebanking. She led the INESS treebanking project, which established an infrastructure for treebanking and created a large LFG treebank for Norwegian. Recently she has been working with multiword expressions and how they are represented in treebanks.

\section{Martha Thunes}

- Western Norway University of Applied Sciences

Martha Thunes is associate professor of English. She is a general linguist with a background from the University of Bergen. Her research has been centred around EnglishNorwegian contrastive language analysis, combined with theoretical and computational linguistics, translation theory, corpus linguistics, text typology, and studies of language for special purposes. She has worked with treebanking for Norwegian and contributed to NorGramBank. She has published works within natural language processing, general linguistics and contrastive language studies, and her main scientific interests are contrastive linguistics, grammar and the lexicon.

\section{Annie Zaenen}

- Stanford University

Annie Zaenen is adjunct professor in linguistics and also a researcher at the Center for the Study of Language and Information. She is retired from Xerox PARC. She is interested in syntax, lexical semantics, formal issues in grammar and the linguistic side of knowledge representation. She has a theoretical affiliation with Lexical Func- 
tional Grammar but is mainly interested in getting the right generalizations about the interplay of structural constraints, lexical roles, discourse and information structure. 